\title{
Seeing the Landscape through New Eyes: Identifying and incorporating indigenous landscape values into regional planning processes
}

\author{
Darryl Low Choy, Jenny Wadsworth and Darren Burns \\ Griffith University
}

This paper contains traditional cultural knowledge of the South East Queensland indigenous community. It was created with the consent of the Goori/Murri Nation custodians.

\section{Introduction}

Contemporary planning processes have acknowledged the need to embrace regional scale recognition of the values that constitute and give meaning to the regional landscape. Simultaneously, a rapidly increasing body of academic literature is highlighting the relationship between indigenous communities and traditional land within the Australian context (see for examples works by (Toupal 2003; Australian Institute of Aboriginal and Torres Strait Islander Studies (AIATSIS) 2006; McDermott 2006; Venn and Quiggin 2007; CSIRO 2008; SEQTOA 2008; Kijas 2010).

At an international level, there have been increasing calls to acknowledge and respect indigenous rights and culturally diverse values. The 2000 European Landscape Convention and the Guidelines on Indigenous Peoples' Issues (United Nations Permanent Forum on Indigenous Issues 2008) attest to these popular views in public policy.

The European Landscape Convention requires its' signatories to enact legally binding landscape protection, management and planning measures that incorporate the perspectives of all interested groups (Jones 2007). Such measures seek to ensure public participation, decision-making accountability and acknowledgement of the importance of landscape to identity and quality of life. Adding to these intentions, Antrop (2005:23) argues that "The European Landscape Convention essentially aims to bridge the past with future landscapes, but it is not very specific on how to proceed". Throughout the literature, it is evident that existing public policy typically struggles to capture the holistic and changing nature of different values systems and how these are played out in the landscape (Antrop 2005; Bastian, Krönert and Lipský 2006; Berge 2006; Australian Institute of Landscape Architects (AILA) 2009).

\section{Application in Local Practice}

In the planning profession, principles of engagement and protocols for acknowledging traditional knowledge (such as (Australian Institute of Aboriginal and Torres Strait islander Studies 2000; Australian Government 2004) are slowly helping to guide planning practice. A very recent example is the 2009 Queensland State Government's South East Queensland Regional Plan 2009-2031 (The State of Queensland 2009:1). In the case of this Plan, a number of conceptual landscape types have been recognised and accepted by all stakeholders, including the working, protective, supporting, inhabited, leisure, viewed and indigenous landscapes. With the exception of the latter, all of these landscape types have been examined in detail to the point of establishing a clear understanding of their constituent values including their spatial representation at the regional scale. Supporting regional studies include a rural futures study, nature conservation strategy, outdoor recreation strategy, natural resource management study, ecosystem services study and scenic amenity study.

The absence of an appropriate study to establish indigenous landscape values has meant that to date regional planning initiatives have been uninformed of these values. If the Indigenous landscape does not receive the same degree of study and research attention as 
the other competing landscape types its values will not identified and they will be unable to be recognised and accounted for in future policies and planning initiatives.

This paper outlines the beginnings of a process to address this deficiency and identify indigenous landscape values for the purposes of accounting for them in statutory planning at the regional scale within a values led planning process. It describes the current outputs from a pilot study of indigenous landscape values for the South East Queensland (SEQ) region ${ }^{1}$. The research question that guided this study was:

Can indigenous landscape values be identified and represented in ways that respect indigenous culture and represent their interest in conventional regional planning processes?

\section{Methodology}

The research question was addressed through a case study approach based on SEQ. A preliminary review of relevant academic literature was conducted to:

- $\quad$ scope the extent to which indigenous perspectives are being incorporated into public policy;

- verify the appropriateness of the regional landscape scale;

- define values and their relevance to planning; and

- scope international and national knowledge of indigenous landscape values.

The adopted SEQ case study was based on the four indigenous sub-regions of SEQ, depicted in Figure 1. This geographic subdivision of the region is in accordance with acknowledged Traditional Owner's lines. Given the regional scale of strategic planning activities in Queensland, it was imperative to establish whether the landscape values of the indigenous community were applicable at this scale. In light of this, two regional-scale workshops were conducted involving the indigenous community of SEQ (including both Traditional Owners and Non-Traditional Owners). This inclusive approach acknowledged that any member of the indigenous community is subject to the traditional protocols of the area. SEQTOA's established reputation and contact network (amongst Traditional Owners and Non-Traditional Owners) enabled them to serve as gatekeepers to the region's indigenous community during this research including the engagement of workshop participants.

Each workshop opened with a 'Welcome to Country' followed by a cultural performance by a local indigenous cultural group. The performance highlighted the regional landscape as the common frame of reference for the workshop activities and for the overall research. The workshops addressed the articulation of indigenous landscape values for the region and the range of their representation. Workshop activities were structured around questions such as 'What is it in the regional landscape of the Goori/Murri Nation that is important and has value to you?'; 'How is information on this element/value communicated?' and 'How have these elements/values changed over time?'. To support these answers, participants were asked to 'Describe specific examples and representations of the landscape elements/values in your sub-region'. To establish a degree of consensus, minimise the effect of individual biases towards certain information discussed in the workshops and to maintain academic rigour

\footnotetext{
${ }^{1}$ This study took the form of a twelve month pilot project conducted under the auspices of the Griffith University Industry Collaborative Scheme. Funding partners included Griffith University, SEQ Catchments and the former Office of Urban Management (now Department of Infrastructure and Planning). The South East Queensland Traditional Owners Alliance (SEQTOA) was also an important research partner. SEQTOA is the peak body formed by Traditional Owner cultural groups in SEQ to represent and advance their interests in cultural and natural resource management.
} 
only those workshop findings that could be verified from other sources (Steele 1983; Wells 2003; King and Crosby 2004; SEQTOA 2008).

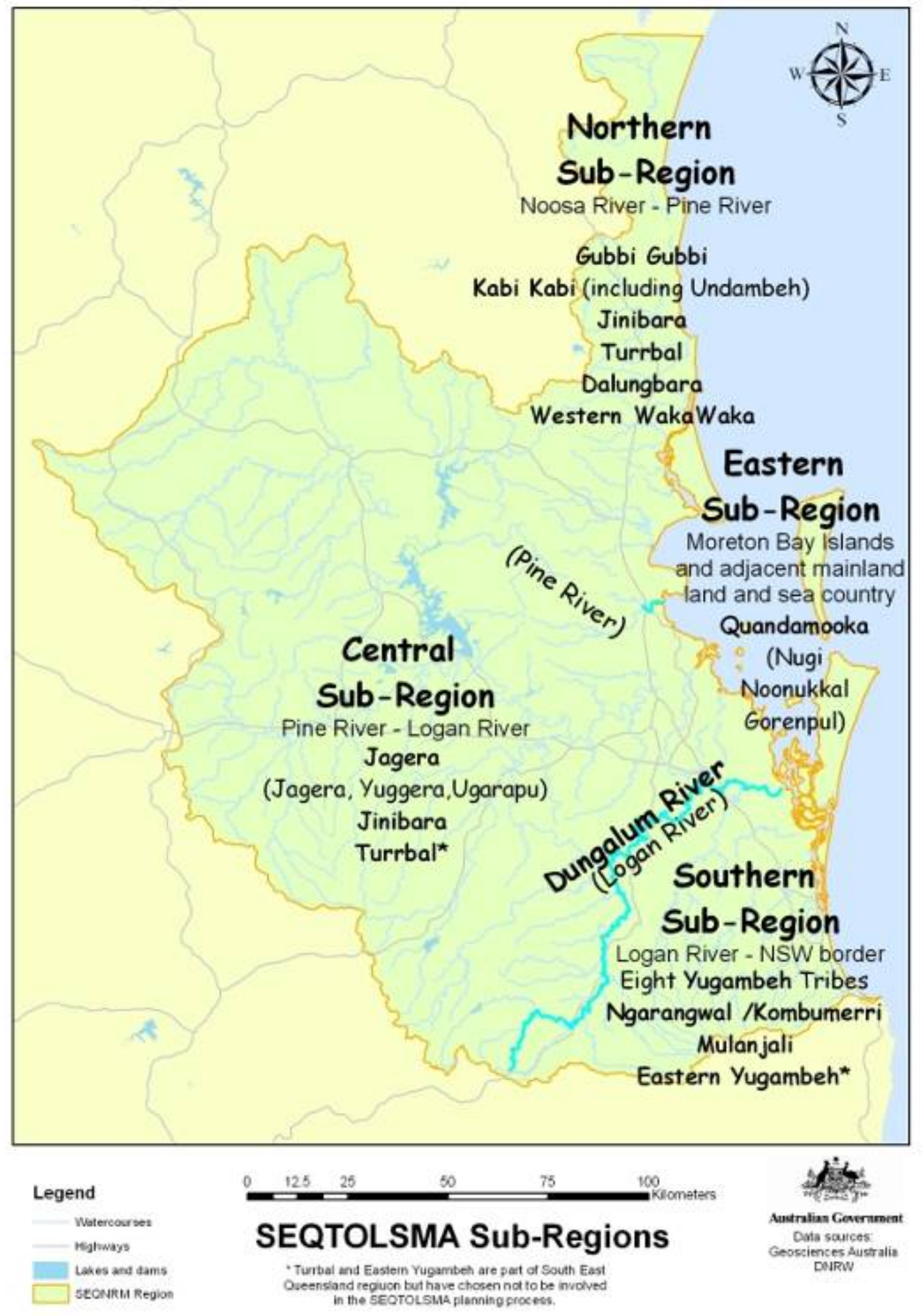

Figure 1: Sub-Regional Indigenous Groups of South East Queensland (Source: SEQTOA 2008, formerly SEQTOLSMA) 


\section{Expressing Landscape Values through Regional Planning}

Importantly the landscapes that are the subject of contemporary regional planning endeavours need to be understood as dynamic landscapes. Whilst reflecting past and present values, they are constantly undergoing change through human interaction, occupation and exploitation. The European Landscape Convention defines landscape as 'an area, as perceived by people, whose character is the result of action and interaction of natural and/or human factors' (Antrop 2005; Jones 2007). Essentially, at the landscape scale we can observe the relationship between people and place (Bohnet, Kinjun and Roberts 2006; Selman 2006). The regional scale is currently attracting a lot of academic and political attention in the search for sustainable outcomes for the landscape (Keogh, Chant and Frazer 2006; Commonwealth of Australia 2008; Wheeler 2009). At the regional scale, it is possible to see this nexus between the localised 'place-based' experiences of people and common geographical, biophysical, economic and social features in the regional landscape.

In seeking to better understand how people interpret 'place', researchers have tended to focus on the socially constructed elements of place as opposed to physical landscape features (Stedman 2003:671; Selman 2006). Natural forces (such as climatological, fluvial and geomorphologic processes) influence continual change in the regional landscape. Through testing multiple scenarios, Stedman (2003) found that people rely heavily on physical landscape features as the basis for their interpretation of place. This shows that our experiences (and the meanings we attach to features), our place attachment ('emotional bond') and our place satisfaction are significantly connected to the regional landscape (Stedman 2003:682).

The regional landscape simultaneously embodies our heritage as well as opportunities for the future (Antrop 2005; Stephenson 2008). There are numerous case studies in the literature highlighting the difficulty of maintaining a strong sense of connection to the landscape when it undergoes radical change (Terkenli 2001; Lewis and Sheppard 2005; Peil 2006; Bergman, Ostlund, Zackrisson and Liedgren 2008; Stephenson 2008). In addition to natural changes, the functions performed by the regional landscape also change with the cultural, social and economic conditions. For example, Bergman et al. (2008:1) explains that northern Scandinavian landscapes were once "laden with religious significance" for the native Sami people, however conflict with Swedish and Christian societies led to an almost complete annihilation of those landscape elements and values. Forced abandonment of the traditional way of life for Sami people has left a fragmented oral history and place names as the only remnants of the traditional regional landscape. This raises the question of whether a similar situation occurred in the transition from traditional to post-colonial landscapes in Australia.

In addressing indigenous landscape values, it is important to ascertain how they align with the values led approaches upon which much current planning practices, including those undertaken within the SEQ context are based (Thomas 1994; Upton 2002). Values represent our different perspectives on what is important in the world and in our community. Values are a significant component of 'culture' (Hawkes 2001) and have the potential to significantly influence planning and its physical outcomes in an area:

Public planning, at all tiers of government, is the crucible in which ... the most coherent expression of a society's aspirations may emerge - if, that is, the planning processes are themselves imbued with the values of the society those processes serve.

... sometimes these values are formally expressed, more often, they are simply assumed. (Hawkes 2001:5)

Contemporary concepts of the 'regional landscape' acknowledge that it embodies through its open space a range of community based values including high biodiversity, high scenic 
amenity, good quality agricultural land, sustainable nature based recreation opportunities, ecosystem services and important cultural heritage of recognised community significance (including indigenous and non-indigenous values) (Low Choy 2004; Low Choy 2008). The increasing uptake of 'values-led' planning approaches has encouraged the formal identification of these community values in a number of State planning systems in Australia, including the South East Queensland Regional Plan 2009-2036 as previously discussed.

However, regional planning processes Australian-wide have been entirely devoid of agreed indigenous landscape values. Consequently, these regional planning processes have proceeded without the same degree of understanding of indigenous landscape values as for the other competing landscape types (Jackson 2008). Tuan (2001), commenting on the Indigenous Australian relationship to the land, emphasised the distinct types of landscape meaning (social, ceremonial and survival) evident at the regional scale, that is, "the home of the ancestors, the dreaming place where every incident in legend and myth is firmly fixed in some unchanging aspect of nature - rocks, hills and mountains, even trees, for trees can outlive human generations" (Tuan 2001:157). The appropriateness of the regional scale for consideration of indigenous landscape values is also supported by the work of King and Crosby (2004:8): "For Aboriginal activity... it is best to view the area within its wider regional context, which incorporates all the various elements of season, environment, social interactions, ceremony and resource availability".

A vast array of literature notes that indigenous knowledge and values are seemingly "incompatible" with contemporary European values, in terms of format and structure (Baker, Sipe and Gleeson 2006; Brown 2006; Dramstad, Tveit, Fjellstad and Fry 2006; Lane 2006; Jones 2007; Jackson 2008; Pawu-Kurlpurlurnu, Holmes and Box 2008; Stephenson 2008). Perhaps most significantly, the place-specificity of regional landscape values does not necessarily mean that they can be spatially expressed. As a result, it is worthwhile for planners to critically assess the wide variety of different disciplinary approaches to representing indigenous landscape values. Examples include cartographic techniques (Dramstad et al. 2006; Peil 2006; Brown and Raymond 2007), landscape visualisation techniques (MacFarlane, Stagg, Turner and Lievesley 2005; Dramstad et al. 2006; Lewis and Sheppard 2006), digital techniques (Ervin and Hasbrouck 2001; Leavy, Wyeld, Hills, Barker and Gard 2007; Australian Cultural Resource Centre for Interaction Design 2008) and even more unconventional techniques such as indigenous foodscapes (Panelli and Tipa 2008).

A number of works have attempted to capture the complex, interrelated and dynamic nature of indigenous values (King and Crosby 2004; Australian Institute of Aboriginal and Torres Strait Islander Studies (AIATSIS) 2006; Stephenson 2008). 'Sense of place' has become a dominant concept for thinking about the holistic relationship between people and the natural environment (Stedman 2003). An Australian case study that exemplifies 'sense of place' and strongly correlates with the findings of this research is the Ngurra-kurlu concept (PawuKurlpurlurnu et al. 2008). Ngurra-kurlu highlights the interconnection of the physical landscape (country) with the language, law, identity / kinship (skin) and ceremonial features of indigenous society. In other words, the landscape, belief system and way of life for indigenous peoples are all inextricably linked.

Both planning theory and practice have recognised the importance of balancing different sets of values (Bohnet and Smith 2007; Stephenson 2008). Stephenson (2008:138) argues that

"While it is unnecessary for different forms of landscape knowledge to share a methodology or a theoretical foundation, the key is a common frame of reference that has a reasonable fit with the range of ways in which disciplines and communities perceive and value landscape". 
Although Stephenson's Cultural Values Model (Figure 2) is yet to be rigorously tested and critiqued, it may be a useful framework capable of drawing together the wide range of possible values and representations.

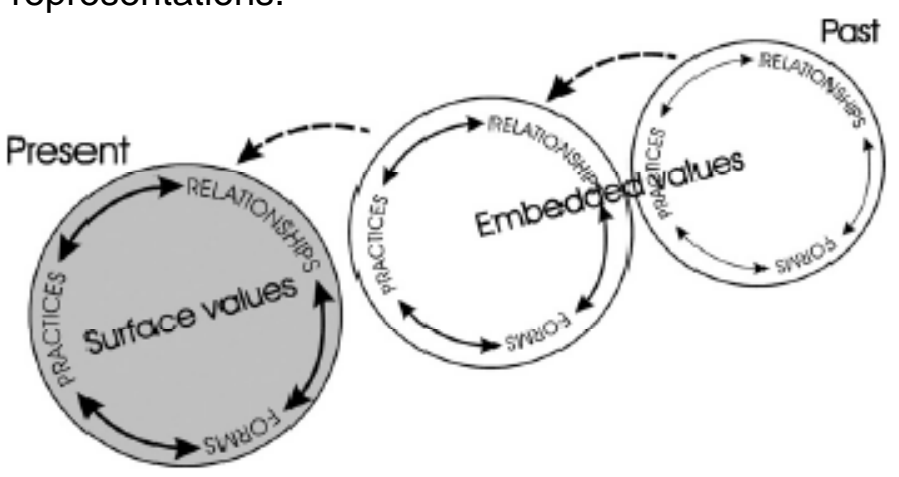

Figure 2: Cultural Values Model

(Source: (Stephenson 2008:136)

This model uses three categories of landscape values, namely forms, practices and relationships, and shows that these values interact and change over time. The distinction between surface and embedded values acknowledges the difference between values that are immediately recognisable in the contemporary landscape and values that involve an awareness of past landscapes.

In summary, there is a strong call throughout the literature to understand and incorporate indigenous landscape values in planning. However, maintaining the integrity of those values is equally as important as producing an actionable and sustainable process that fits within existing regional planning processes.

\section{Results and Analysis}

From the outset, Indigenous landscape values need to be understood within their temporal dimensions. Whilst the values that indigenous people place on the regional landscape can be identified according to their importance in the current, historical and / or spiritual realms, most of the values in fact are significant across all realms of indigenous life. Despite the fact that there is general agreement on most of the values, there are also subtle differences of (personal and sub-regional) opinion on how the values are related to each other and to their connectedness to country. Connection to country is fundamentally derived from the spiritual realm through an understanding of the ancestral origin, genesis and creation of features in the regional landscape. This spiritual connection with country underpins indigenous belief systems and identity. It is not only relevant to the past, but also governs appropriate ways of being and operating in the present. Thus, connection to country pervades all elements and values of the regional landscape.

In terms of thematic diversity, the value sets derived from the identification of landscape elements considered important to indigenous society appear to offer an extremely wide range. Although the terms 'elements' and 'values' were initially combined as prompts during the research, it is necessary to make a clear conceptual distinction between these concepts in subsequent discussion. Elements are a geographical component or feature of the regional landscape, such as rivers, lakes, mountains, valleys and rocks. Values on the other hand are things (such as beliefs and ideals) that are considered important to people. Thus, values are highly subjective. As previously noted these elements and value sets have been verified with a number of other sources (Steele 1983; Wells 2003; King and Crosby 2004; SEQTOA 2008). 
Four elements stood out as key defining landscape elements for the indigenous community through which their values of the regional landscape can be understood. All exhibited clear links to contemporary non-indigenous physical landscape planning and included:

- Boundaries

- Pathways

- Biodiversity matters

- Important sites / areas

Boundaries

Traditional boundaries are a significant component of the indigenous way of life for both individuals as well as the interactions of larger groups. They help to define 'country' ("where I belong") and contribute to sense of place. Figure 3 illustrates this relationship. Traditional boundaries are created and perpetuated through lore, law, custom and kinship, in line with the spiritual beliefs of the people.

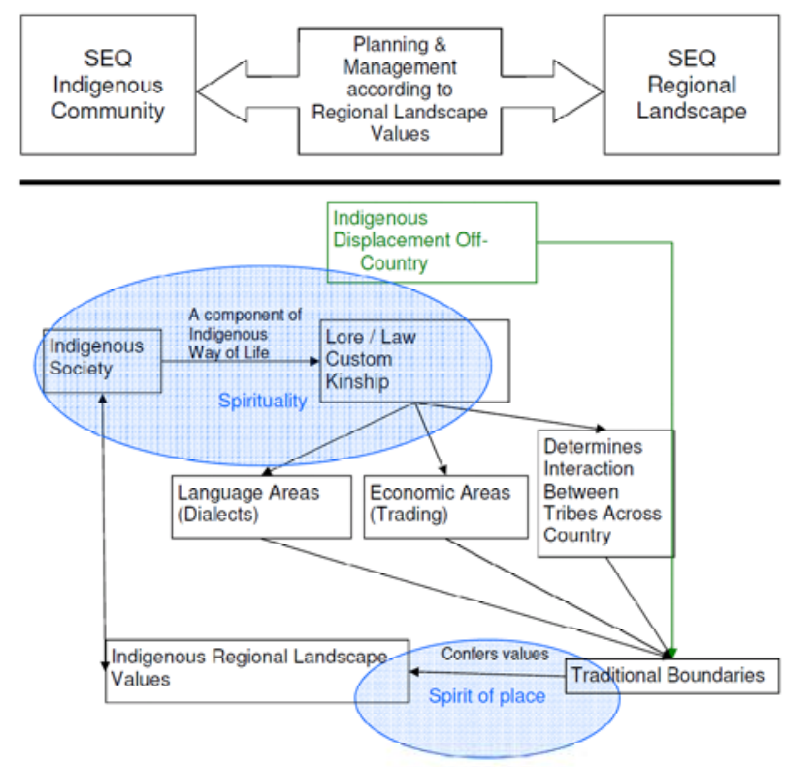

Figure 3: Conceptual diagram showing the relationship between the SEQ indigenous community and traditional boundaries in the regional landscape.

(Source: (Low Choy, Wadsworth and Burns 2009))

In the SEQ context, three types of traditional boundaries exist, namely: natural boundaries, invented boundaries and language boundaries. Natural boundaries are landscape features that create an obvious division in the landscape, such as creeks, rivers, channels, mountains and mountain ranges. Natural boundaries are a common way of distinguishing between tribal territories and thus, are strictly protected. One example is the Northern Scenic Rim forming a boundary for the Central sub-region. In addition to these large landscape features, tracks, rocks, vegetation types and fauna areas are used to recognise all three types of boundaries.

Invented and language boundaries are more intangible elements. Invented boundaries are typically created through myth and stories for purposes such as community safety (eg to prevent children from accessing a potential harmful location). Forbidden areas and dangerous natural features, such as swamps, lakes and snake habitats, can be addressed by creating a notional limit to access. Language boundaries are based on the degree of similarity or difference in the dialects and languages across the region. SEQ's four subregions are roughly based upon similar language groups. 
Some traditional boundaries have changed over time and others may be contested. Changes can occur with 'ownership' of territory (and location of boundaries) being negotiated through law and custom. For example, expansion of territory (and access to resources) was often necessary when clans grew in size or kinship changed (such as intertribal marriages). In other cases however, the changes resulted from battles over country and thus, traditional boundaries became battlefield sites in these locations. Native title and land council negotiations have forced adjustment of traditional boundaries in many cases. In these circumstances it is difficult to map a definite boundary. Traditionally, boundaries are not narrow lines but wide areas that can be walked through (pathways) and to some extent form common ground between groups.

Hence, the existence of traditional boundaries across the SEQ landscape, in their many forms, serves to delineate a spirit of place which confers particular indigenous values to those regional landscapes.

\section{Pathways}

Pathways are passages of land or water used to move through the landscape. The nature and location of pathways depends upon the availability of food, water and shelter (to sustain the journey) and safe, easily negotiated routes that link the journey's origin and destination. This relationship is highlighted in Figure 4. Pathways typically connect different groups of people and important sites (including boundary corners, sacred, ceremonial, meeting and habitation sites).

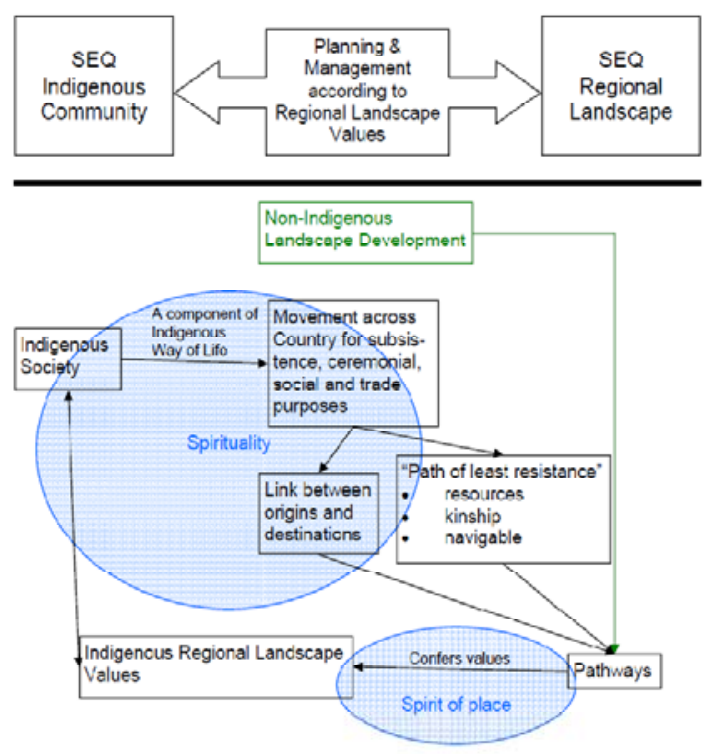

Figure 4: Conceptual diagram showing the relationship between the SEQ indigenous community and pathways in the regional landscape

(Source: (Low Choy et al. 2009))

Valleys, wildlife corridors, beaches / shorelines, waterways / channels / currents and tides and ridgelines are frequently recognised as pathways. These pathways were (and still are) used as social, trade and seasonal routes. In some locations, the construction of transport infrastructure along pathways has destroyed the important sites at the origins or destinations of that pathway.

The existence of pathways across the SEQ landscape, serves to delineate a spirit of place which confers particular indigenous values to those regional landscapes. 
A fundamental concept underpinning indigenous spirituality is that indigenous people (and their ancestors) are part of the landscape. It follows that they have an acute sense of even small biodiversity changes. There are three main ways that biodiversity is identified in the regional landscape:

- Interpretation of 'bush calendar' (including animal behaviour, flowering and growth seasons)

- Interpretation of indicators and warning signs (especially from fauna)

- Presence and absence of totemic species and their habitats

A totem is typically an animal or plant species that is in some way connected to, associated with, and / or representative of, a clan group, family or even an individual. Figure shows this relationship to the elements of the landscape. In SEQ, the spatial distribution of flora and fauna species was considered the primary factor influencing which totems are assigned to which people. This means that when traversing the landscape, the presence or absence of different species (and their respective habitats) indicates the territory of different totemic groups.

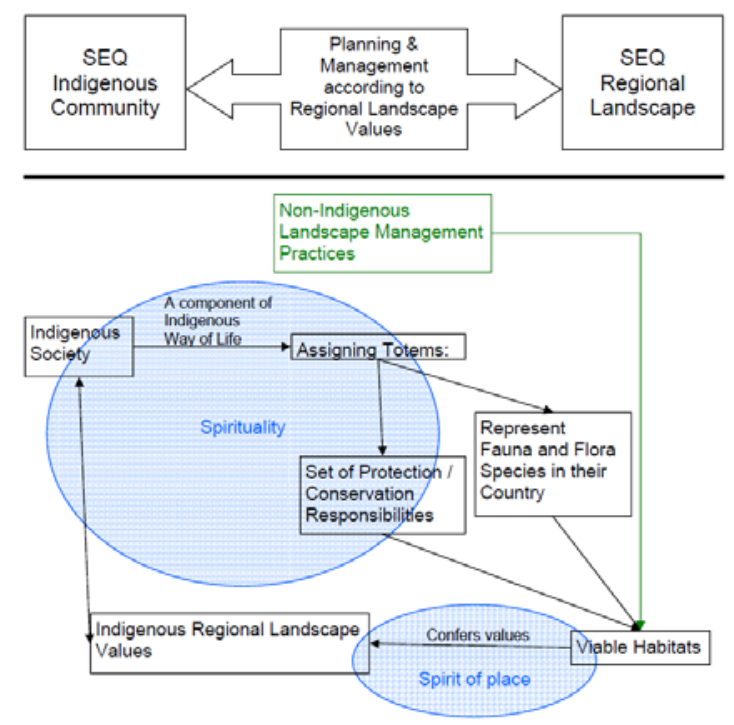

Figure 5: Conceptual diagram showing the relationship between the SEQ indigenous community and biodiversity in the regional landscape

(Source: (Low Choy et al. 2009))

Totemic identity creates an unbreakable spiritual connection between the regional landscape and each individual. It creates a set of protection and conservation responsibilities, such as not eating your own totem and carrying out landscape management techniques that will ensure its' prosperity. The well-being of the individual, the totem (and its respective habitat) and the regional landscape are inextricably linked. Deep knowledge of the totem's spatial distribution and behaviour patterns means that the totem can serve as an indicator of environmental change (whether on a subtle or dramatic scale) and this has also raised the issue whether biodiversity changes can be felt in a spiritual manner. Biodiversity changes (including natural adaptation) influence the way indigenous communities interact with the landscape (and experience connection to country).

Hence, these various biodiversity matters which are linked to the SEQ landscape contribute to defining a spirit of place which confers particular indigenous values to those regional landscapes. 
This category is an agglomeration of several elements, including, women's and men's places, ceremonial areas, habitation sites, mission sites and battlefield sites. These important sites and areas typically either have restricted access or serve as places of social interaction ('common ground'). Figure 6 illustrates the relationships between these Indigenous significant sites and areas and the regional landscape.

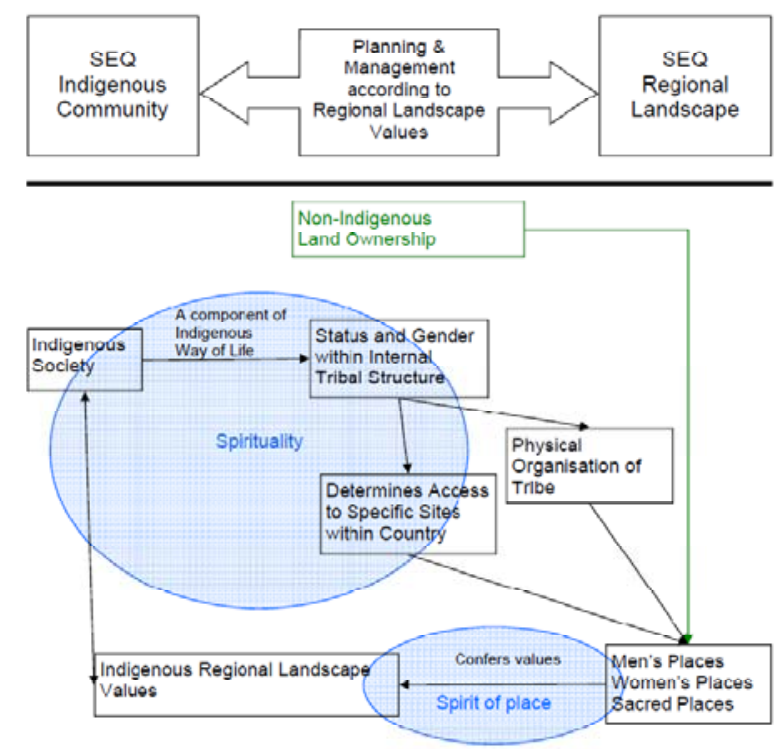

Figure 6: Conceptual diagram showing the relationship between the SEQ indigenous community and important sites in the regional landscape

(Source: (Low Choy et al. 2009))

Gaining permission to access women's and men's places and ceremonial areas depends upon kinship structures in the area, the status of the person wishing to visit and the specific circumstance. Despite the fact that such places are only accessible to certain people at particular times, these places still hold significance for the wider indigenous community.

Some ceremonial areas, festival sites and corroborree (meeting / gathering) sites have restricted access for important events whilst others are a fundamental part of internal and external social relations for indigenous communities. Specific indigenous sites such as bora grounds and kippa rings are areas used for meetings and ceremonies (and can typically be identified as a circular space(s) with raised sides for seating purposes). Real and ceremonial/mock battlefield sites between tribes were not necessarily specific identifiable locations and there is evidence of battle preparation sites throughout the regional landscape.

Traditional habitation areas, battlefields and mission sites were dependent on the availability of food, water, firewood and other resources. Traditional habitation areas were typically sited on elevated land. In the Eastern sub-region, Myora Swamp at Amity was originally the Moongalba traditional campsite (in a strategic resource and meeting location), later becoming a battle and mission site. The battles between Indigenous and European groups were primarily linked to the productive capacity of the land and its' suitability for occupation. As a result, European land holdings and production areas often replaced important sites and areas for indigenous communities with the latter being relocated to resource-depleted and remote mission sites.

Again, the existence of these important sites and areas have special significance to Indigenous communities and to their spirit of place establishing a unique set of values to the regional landscapes containing those sites and areas. 


\section{Discussion}

This pilot study confirmed the validity of the regional approach to the incorporation of indigenous landscape values into regional planning from both an academic perspective and for the current planning endeavours for the SEQ region. This region is known to the indigenous community as the Murri nation and thus, the Indigenous community feels comfortable thinking collectively at this scale. Furthermore, the sub-regional language groups proved to be effective for looking at more place-based examples of the landscape values. The sub-regional geographic subdivision of the region that acknowledges the various Indigenous language groups has been confirmed as a useful organising framework for research into Indigenous landscape values.

It is evident that indigenous landscape values are holistic and interconnected; physical and spiritual; non-living and living; past, present and future. Traditional boundaries, pathways, biodiversity matters and important sites and areas were selected as four key landscape elements that underpin numerous indigenous values. These four elements also show significant potential for integration into existing planning policy in SEQ. The biodiversity findings, for example, provide insight into possible mechanisms to enhance the sustainability of regional planning practices. The strong relationship between indigenous people and the natural landscape (created through totemic identity) ensured sustainable landscape management throughout pre-colonial Australian history. Post colonisation, most indigenous communities were either displaced from their traditional lands or lost control of their traditional land to non-indigenous landscape management practices. In these circumstances, totemic identity is significantly undermined and individuals are unable to fulfil their spiritual responsibilities to country. Thus, the well-being (and viable habitat) of totemic species is compromised. Inevitably, this also compromises the physical, emotional and spiritual wellbeing of indigenous people. It is worth asking whether the process of assigning responsibility to inhabitants of the land is a viable technique for contemporary landscape planning and management.

The conceptual diagrams, depicted in Figures 3 to 6 , attempt to convey the complexity of the relationship between the SEQ indigenous community and the regional landscape. These schemas acknowledge the spiritual significance (and value) of the relationship as well as the major external influences that can prevent the realisation or protection of the value.

Figure positions regional planning activities (guided by community values) as central to the ongoing relationship between the regional landscape and the Indigenous community in SEQ. This in itself could be a potentially important prospect for the reconciliation process within SEQ. Figure 7 highlights how key defining landscape elements, such as: boundaries; pathways; biodiversity matters; and important sites / areas can have special significance to Indigenous communities and to their spirit of place establishing a unique set of values to the regional landscapes containing those key elements. 


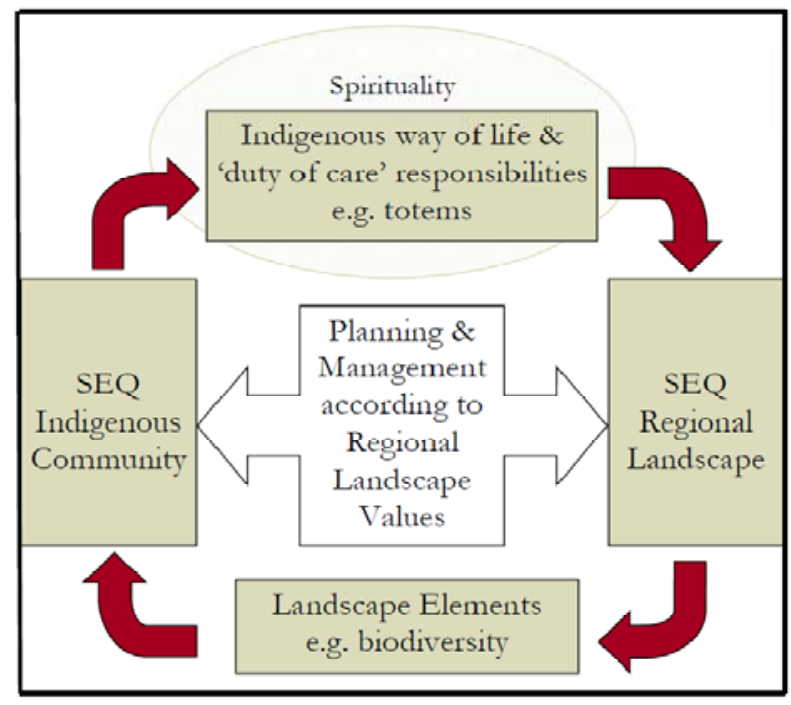

Figure 7: Conceptual overview of the relationship between Indigenous landscape values and the SEQ regional landscape

Contemporary regional planning activities do not currently address the various methods of acknowledging, representing or integrating different cultural values sets discussed in the literature. However, the four landscape elements identified in this preliminary research align with the current and ongoing planning commitments of the principal agencies responsible for land use and environmental planning and natural resource management in SEQ. Thus, these research findings offer a promising starting point to enhance the cultural accountability and sustainability of contemporary regional planning in SEQ. It is of interest to note that this process has commenced with the citation of the pilot study of this research in the recent 2009 SEQ Regional Plan.

\section{Conclusion}

Across the international fields of public policy, landscape and environmental management and strategic land use planning in particular, there are increasing calls to acknowledge and respect indigenous rights and culturally diverse values. This is especially important for South East Queensland, given that it has adopted a ('best practice') values-led strategic regional planning approach. Thus it is at the regional scale in the SEQ context, where landscape values first intersect in the public policy domain and consequently set this initial scale of inquiry.

It has been established that it is possible to identify indigenous landscape values at the regional scale in SEQ. The four key elements of boundaries, pathways, biodiversity matters, and important sites / areas have been recognised as highlighting a clear relationship to the regional landscape with the potential to define a specific set of landscape values in relation to the Indigenous communities' connection to country (ie to the SEQ regional landscape). These key elements show the greatest potential to offer a positive way to incorporate Indigenous landscape values into conventional regional planning processes. Once achieved, the regional planning process will be more robust as it not only will incorporate a fuller range of landscape values but through its process it will have reconciled these values, attempted to resolve conflicting values and prioritised the management of agreed landscape values for the region. These findings provide a solid foundation for further investigation into indigenous landscape values and strategic regional planning ${ }^{2}$. Future research must

\footnotetext{
${ }^{2}$ This pilot study is now being extended into a full two year ARC Linkage project aimed at addressing the full extent of the research question, especially in regard to the incorporation of identified
} 
endeavour to balance academic rigour, respect for indigenous perspectives and the practicalities of current regional planning practices in order to produce meaningful outcomes. In this manner, future planning endeavours can be better informed about the full array of regional landscape values and such a plan will truly be capable of claiming that it is seeing the landscape through new eyes.

\section{References}

Antrop, M. 2005. "Why landscapes of the past are important for the future". Landscape and Urban Planning 70(1-2):21-34.

Australian Cultural Resource Centre for Interaction Design. 2008. "Digital Songlines". accessed on 27 August 2008.

http://songlines.interactiondesign.com.au/index.php?option=com frontpage\&ltemid=1. Australian Government. 2004. "Working with Indigenous Knowledge in Natural Resource Management: Guidelines for Regional Bodies". Commonwealth of Australia

Australian Institute of Aboriginal and Torres Strait islander Studies. 2000. "Guidelines for Ethical Research in Indigenous Studies". Australian Indigenous Law Reporter 12(8):1.

Australian Institute of Aboriginal and Torres Strait Islander Studies (AIATSIS). 2006. "Sea countries of the south: Indigenous interests and connections within the South-west Marine Region of Australia". Canberra: Australian Institute of Aboriginal and Torres Strait Islander Studies.

Australian Institute of Landscape Architects (AILA). 2009. "Putting a Value on Landscape: a strategic framework for planning, design and management of our urban environment". Canberra: Part of Adapting to Climate Change series, funded by Department of Climate Change's Climate Change Adaptation Skills for Professionals Program.

Baker, D.C., N.G. Sipe, and B.J. Gleeson. 2006. "Performance-Based Planning:

Perspectives from the United States, Australia, and New Zealand". Journal of Planning Education and Research 25(4).

Bastian, O., R. Krönert, and Z. Lipský. 2006. "Landscape Diagnosis on Different Space and Time Scales-A Challenge for Landscape Planning". Landscape Ecology 21(3):359-374.

Berge, E. 2006. "Protected areas and traditional commons: Values and institutions". Norwegian Journal of Geography 60(1):65-76.

Bergman, I., L. Ostlund, O. Zackrisson, and L. Liedgren. 2008. "Varro Muorra: The Landscape Significance of Sami Sacred Wooden Objects and Sacrificial Altars".

Ethnohistory 55(1):27.

Bohnet, I., C. Kinjun, and B. Roberts. 2006. "Community uses of and values attached to waters in the Tully-Murray catchment". Pp. 58

Bohnet, I.and D. Smith. 2007. "Planning future landscapes in the Wet Tropics of Australia: A social-ecological framework". Landscape and Urban Planning 80(1-2):137-152.

Brown, G. 2006. "Mapping landscape values and development preferences: a method for tourism and residential development planning". International Journal of Tourism Research 8(2):13, 101-113.

Brown, G.and C. Raymond. 2007. "The relationship between place attachment and landscape values: Toward mapping place attachment". Applied Geography 27(2):89-111. Commonwealth of Australia. 2008. "Regional Development Council website". Department of Infrastructure, Transport, Regional Development and Local Government accessed on 29 August 2009. http://www.rdcouncil.gov.au/framework/index.aspx.

CSIRO. 2008. "Aboriginal land and sea management in the Top End: a community-driven evaluation". Northern Territory: CSIRO Sustainable Ecosystems.

indigenous landscape values into the conventional regional planning process active in the SEQ region. 
Dramstad, W., M. Tveit, W. Fjellstad, and G. Fry. 2006. "Relationships between visual landscape preferences and map-based indicators of landscape structure". Landscape and Urban Planning 78(4):465-474.

Ervin, S.M.and H.H. Hasbrouck. 2001. Landscape Modeling: Digital Techniques for Landscape Visualization: McGraw-Hill Professional.

Hawkes, J. 2001. "The Fourth Pillar of Sustainability". Urbana Illinois: Common Ground Publishing.

Jackson, S. 2008. "Recognition of Indigenous Interests in Australian Water Resource Management, with Particular Reference to Environmental Flow Assessment". Geography Compass 2(3).

Jones, E.R. 2007. "Three Management Challenges for Protection of Aboriginal Cultural Heritage in a Tasmanian Multiple-use Conservation Area". Australian Geographer 38(1):93112.

Keogh, K., D. Chant, and B. Frazer. 2006. "Review of arrangements for regional delivery of natural resource management programmes". Canberra: Australian Government.

Kijas, J. 2010. "Same place, different views: Exploring the Wilsons River story sites community history project". The Public Historian 32(2):51-60.

King, B.and E. Crosby. 2004. "Cultural Heritage Survey \& Study: Coombabah Lakelands Conservation Area \& Environs ". Gold Coast City Council.

Lane, M.B. 2006. "The role of planning in achieving indigenous land justice and community goals". Land Use Policy 23(4):385-394.

Leavy, B., T. Wyeld, J. Hills, C. Barker, and S. Gard. 2007. "Digital Songlines: digitising the arts, culture and heritage landscape of Aboriginal Australia". New Heritage: New Media And Cultural Heritage.

Lewis, J.L.and S.R.J. Sheppard. 2005. "Ancient Values, New Challenges: Indigenous Spiritual Perceptions of Landscapes and Forest Management". Society \& Natural Resources 18(10):907-920.

—. 2006. "Culture and communication: Can landscape visualization improve forest management consultation with indigenous communities?". Landscape and Urban Planning 77(3):291-313.

Low Choy, D.C. 2004. "The Regional Open Space Paradox". Queensland Planner 44(3):1215.

—. 2008. "The SEQ Regional Landscape Framework: Is Practice Ahead of Theory?". Urban Policy and Research 26(1):111-124.

Low Choy, D.C., J. Wadsworth, and D. Burns. 2009. "Identifying and Incorporating Indigenous Landscape Values into Regional Planning Processes". Brisbane: Griffith University.

MacFarlane, R., H. Stagg, K. Turner, and M. Lievesley. 2005. "Peering through the smoke? Tensions in landscape visualisation". Computers, Environment and Urban Systems 29(3):341-359.

McDermott, C. 2006. "Mapping country- a landscape approach to cultural heritage and biodiversity (online)". in NSW Biodiversity Research Network Newsletter

Panelli, R.and G. Tipa. 2008. "Beyond foodscapes: considering geographies of Indigenous well-being". Health \& Place.

Pawu-Kurlpurlurnu, W.J., M. Holmes, and L. Box. 2008. "Ngurra-kurlu: A way of working with Warlpiri people".

Peil, T. 2006. "Maps of meaning: Landscapes on the map and in the mind discovering Paldiski, Estonia". Norsk Geografisk Tidsskrift - Norwegian Journal of Geography 60(1):110 122.

Selman, P.H. 2006. Planning at the Landscape Scale: Routledge.

SEQTOA. 2008. "Our Plan: The South East Queensland Traditional Owner Cultural Resource Management Plan". Brisbane: South East Queensland Traditional Owners Alliance Ltd.

Stedman, R.C. 2003. "Is It Really Just a Social Construction?: The Contribution of the Physical Environment to Sense of Place". Society \& Natural Resources 16(8):671-685. 
Steele, J.G. 1983. Aboriginal Pathways in Southeast Queensland and the Richmond River St Lucia: University of Queensland Press.

Stephenson, J. 2008. "The Cultural Values Model: An integrated approach to values in landscapes". Landscape and Urban Planning 84(2):127-139.

Terkenli, T. 2001. "Towards a theory of the landscape: the Aegean landscape as a cultural image". Landscape and Urban Planning 57(3-4):197-208.

The State of Queensland. 2009. "South East Queensland Regional Plan 2009-2026". Brisbane: Queensland Government.

Thomas, H. 1994. Values and planning: Avebury.

Toupal, R. 2003. "Cultural landscapes as a methodology for understanding natural resource management impacts in the Western United States (online)". in Conservation Ecology

Tuan, Y.F. 2001. Space and Place: The Perspective of Experience: University of Minnesota Press.

United Nations Permanent Forum on Indigenous Issues. 2008. "Resource Kit on Indigenous Peoples' Issues". United Nations Permanent Forum on Indigenous Issues.

Upton, R. 2002. "Planning praxis: ethics, values and theory". Town Planning Review 73(3):253-269.

Venn, T.J.and J. Quiggin. 2007. "Accommodating indigenous cultural heritage values in resource assessment: Cape York peninsula and the Murray-Darling basin, Australia". Ecological Economics 61(2-3):334-344.

Wells, R.A. 2003. In the Tracks of a Rainbow: Indigenous Culture and Legends of the Sunshine Coast. Sunshine Beach: Gullirae Books.

Wheeler, S. 2009. "Regions, Megaregions, and Sustainability". Regional Studies 43(6):863 876. 